\title{
A critical evaluation of the role of aromatase inhibitors as adjuvant therapy for postmenopausal women with breast cancer
}

\author{
Thierry Petit, Patrick Dufour and lan Tannock ${ }^{1}$
}

Department of Medical Oncology, Paul Strauss Cancer Center, and University of Strasbourg, 3 rue de la Porte de l'Hôpital - BP42, F-67065 Strasbourg, France

${ }^{1}$ Division of Medical Oncology and Haematology, Princess Margaret Hospital and University of Toronto, Toronto M5G 2M9, Canada (Correspondence should be addressed to T Petit; Email: tpetit@strasbourg.fnclcc.fr)

\begin{abstract}
The introduction of aromatase inhibitors $(\mathrm{Al})$ has provided more options for adjuvant treatment of postmenopausal women; they are associated with improved disease-free survival, but less commonly with improvements in overall survival. Current evidence suggests that women at high risk of recurrence, especially those with node-positive disease, should receive an Al for 2 years as part of their treatment, but routine prescription of Als to postmenopausal patients with low-risk disease is not appropriate. Not only the expected benefits but also the specific toxicity of the prescribed hormone therapy, and its cost, should be considered when selecting treatment.
\end{abstract}

Endocrine-Related Cancer (2011) 18 R79-R89

\section{Introduction}

In 1836, Sir Astley Cooper from St Bartholomew's Hospital in London described, in a patient suffering from breast cancer, a correlation between tumour proliferation and the menstrual cycle (Brock 1952). Georges Beatson, a Glasgow surgeon, undertook the first hormone-targeted therapy in 1896, performing oophorectomy in two premenopausal women with breast cancer. Castration resulted in cancer control for 5 and 8 years. Beatson (1896) concluded that 'the ovaries are the seat of the exciting cause of carcinoma, certainly of the mamma...'. It is now known that about $75 \%$ of breast cancers express oestrogen receptors and that tumour cell proliferation depends on oestrogen concentration (Harris et al. 2006).

Medical hormone therapy started in the 1940s with the use of the non-steroidal oestrogen diethylstilbestrol (DES) that acted as an oestrogen antagonist in pharmacological concentration (Dodds 1948). Tamoxifen, a selective oestrogen receptor modulator, was first prescribed in 1971 and showed similar efficacy to DES but better tolerance (Cole et al. 1971). Since 1986, tamoxifen has been prescribed in the adjuvant setting to postmenopausal patients with axillary lymph node involvement, and since 1990, it has been administered to both premenopausal and postmenopausal women with and without lymph node involvement (Early Breast Cancer Trialists' Collaborative Group 1998).

Oestrogens are produced by aromatisation of androstenedione to oestrone and testosterone to oestradiol. In premenopausal patients, this largely takes place in the ovary. In postmenopausal patients, this aromatisation mainly occurs in the adrenal glands, but also in adipose tissue, muscles and liver tissue, and there are still circulating oestrogens despite the loss of ovarian function. The active aromatase in postmenopausal women is different from the prevalent form in premenopausal women (Santen \& Harvey 1999). Aromatase inhibitors (AIs) have been designed to inhibit this aromatisation and reduce circulating oestrogen. Several generations of AIs were developed, with improved specificity and efficacy (Smith \& Dowsett 2003), and third-generation AIs in current use are the non-steroidal inhibitors anastrozole and letrozole and the steroidal inhibitor exemestane. These agents are specific for use in postmenopausal women and are ineffective in inhibiting the predominant aromatase of premenopausal women.

The available AIs have greater activity than tamoxifen as first-line treatment in postmenopausal women with metastatic breast cancer. These drugs 
Table 1 Design of studies comparing aromatase inhibitors with tamoxifen for adjuvant treatment of postmenopausal women with breast cancer

\begin{tabular}{llll}
\hline Adopted strategy & Studies & Evaluated Al & \multicolumn{1}{c}{ Randomisation } \\
\hline 'Upfront' & ATAC & Anastrozole & 5-year Al versus 5-year TAM (versus 5-year AI+TAM) \\
& BIG 1-98 & Letrozole & 5-year Al versus 5-year TAM (versus sequence, see below) \\
'Switch' after 2-3 years of TAM & ARNO 95 & Anastrozole & 2/3-year Al versus 2/3-year TAM \\
& ITA & Anastrozole & 2/3-year Al versus 2/3-year TAM \\
& IES & Exemestane & 2/3-year Al versus 2/3-year TAM \\
Sequential approach & ABCSG 8 & Anastrozole & 5-year TAM versus 2-year TAM followed by 3-year Al \\
& BIG 1-98 & Letrozole & 5-year TAM versus 2-year TAM followed by 3-year Al versus \\
& & & 2-year Al followed by 3-year TAM versus 5-year Al \\
Treatment continuation after & AEAM & Exemestane & 2/3-year TAM followed by 2/3-year Al versus 5-year Al \\
5 years of TAM & MBCSG 6a & Anastrozole & 3-year Al versus placebo \\
& MA 17 & Letrozole & 2-year Al versus placebo \\
& NSABP B33 & Exemestane & 5-year Al versus placebo \\
\hline
\end{tabular}

TAM, tamoxifen; AI, aromatase inhibitor.

increase the rate of tumour response and enhance progression-free survival from 6 to 10 months, but none of the randomised studies has shown an improvement in overall survival (Bonneterre et al. 2001, Mouridsen et al. 2003, Paridaens et al. 2008). AIs are now being used as an adjuvant therapy for postmenopausal women with breast cancer, based on the results of several randomised studies comparing tamoxifen and AIs in various schedules (Table 1). In this study, we review those studies and make recommendations about the use of tamoxifen and AIs as adjuvant treatment for postmenopausal women with breast cancer.

\section{Randomised studies with anastrozole}

\section{ATAC trial}

This randomised, double-blind study included initially three treatment arms: a reference arm consisting of tamoxifen for 5 years, an experimental arm with anastrozole for 5 years and a second experimental arm combining tamoxifen and anastrozole (Table 1; Baum et al. 2002). The study included 9366 patients of whom $84 \%$ had a hormone receptor (HoR)-positive tumour, $8 \%$ an HoR-negative tumour and $8 \%$ a tumour with unknown HoR status. Axillary lymph node involvement was present in $35 \%$ of patients. In total, $22 \%$ of patients were also treated with adjuvant chemotherapy (Table 2).

The primary endpoint of the study was disease-free survival (DFS), which involved monitoring of local or distant recurrences, new breast cancers, in situ breast lesions and deaths from any cause (Table 3; Baum et al. 2002).

A first interim analysis was performed after a median follow-up of 33 months. DFS was identical between the reference arm and the experimental

Table 2 Patient characteristics and median follow-up in adjuvant studies comparing tamoxifen and aromatase inhibitors

\begin{tabular}{|c|c|c|c|c|c|c|}
\hline Strategy & Studies & $\begin{array}{l}\text { Number of } \\
\text { patients }\end{array}$ & $\begin{array}{l}\text { Percentage of } \\
\text { patients with } \\
\text { HoR + tumours }\end{array}$ & $\begin{array}{l}\text { Percentage of } \\
\text { patients with } \\
\text { pN+ }\end{array}$ & $\begin{array}{l}\text { Percentage of } \\
\text { patients receiving } \\
\text { chemotherapy }\end{array}$ & $\begin{array}{c}\text { Median } \\
\text { follow-up } \\
\text { (months) }\end{array}$ \\
\hline \multirow[t]{2}{*}{ ‘Upfront' } & ATAC & $6241^{a}$ & 84 & 35 & 22 & 120 \\
\hline & BIG 1-98 & $4922^{a}$ & 100 & 43 & 25 & 76 \\
\hline \multirow{3}{*}{$\begin{array}{l}\text { 'Switch' after } 2 / 3 \text { years } \\
\text { of tamoxifen }\end{array}$} & ARNO 95 & 969 & 97 & 26 & 0 & 30 \\
\hline & ITA & 448 & 100 & 100 & 100 & 36 \\
\hline & IES & 4724 & 86 & 48 & 32 & 55 \\
\hline \multirow[t]{3}{*}{ Sequential approach } & ABCSG 8 & $2921^{b}$ & & 25 & 0 & 72 \\
\hline & BIG 1-98 & $6184^{c}$ & 100 & 43 & 25 & 71 \\
\hline & TEAM & 9775 & & 47 & 36 & 33 \\
\hline \multirow{3}{*}{$\begin{array}{l}\text { Treatment continuation } \\
\text { after } 5 \text { years of } \\
\text { tamoxifen }\end{array}$} & ABCSG 6a & 856 & & 25 & 0 & 60 \\
\hline & MA 17 & 5187 & 98 & 45 & 45 & 30 \\
\hline & NSABP B33 & 1598 & 96 & 48 & 55 & 30 \\
\hline
\end{tabular}

${ }^{a}$ Number of patients for comparison of 5 years of tamoxifen with 5 years of $\mathrm{Al}$.

b2921 patients analysed but 3901 patients randomised originally.

${ }^{\mathrm{c}}$ Number of patients for comparison of sequential approach with 5 years of tamoxifen. 
Table 3 Events considered for assessment of the primary endpoint (event-free, recurrence-free or disease-free survival) in adjuvant studies

\begin{tabular}{|c|c|c|c|c|c|c|c|c|c|c|}
\hline & ATAC & ARNO 95 & ITA & ABCSG 08 & ABCSG 06a & BIG 1-98 & MA 17 & IES & NSABP B33 & TEAM \\
\hline Locoregional recurrence & + & + & + & + & + & + & + & + & + & + \\
\hline Metastatic recurrence & + & + & + & + & + & + & + & + & + & + \\
\hline $\begin{array}{l}\text { Controlateral cancer } \\
\text { In situ lesion }\end{array}$ & $\begin{array}{l}+ \\
+\end{array}$ & + & & + & + & + & + & & & + \\
\hline Other cancers & & & & & & + & & & + & + \\
\hline Death & + & + & & + & & + & & + & + & + \\
\hline
\end{tabular}

arm combining tamoxifen and anastrozole, and this experimental arm was discontinued (Baum et al. 2002). The study continued with 6241 patients included in the two arms comparing tamoxifen and anastrozole alone. A second interim analysis performed after a median follow-up of 68 months showed significant improvement in DFS (hazard ratio $(\mathrm{HR})=$ $0.87 ; P=0.01)$, significant reduction in recurrences $(\mathrm{HR}=0.79 ; P=0.0005)$ and significant reduction in distant recurrences $(\mathrm{HR}=0.86 ; P=0.04$ ) (Howell et al. 2005). There were also less controlateral breast cancers in the anastrozole arm $(\mathrm{HR}=0.56 ; P=0.01)$. These improvements were more pronounced in patients with HoR-positive tumours.

A third interim analysis performed after a median follow-up of 100 months continued to show, for women with HoR-positive tumours, significant improvement in DFS $(\mathrm{HR}=0.85 ; P=0.003)$, significant reduction in recurrences $(\mathrm{HR}=0.76 ; P=0.0001)$ and significant reduction in distant recurrences $(\mathrm{HR}=$ 0.84; $P=0.022$ ) (Forbes et al. 2008). Absolute event reduction was $2.5 \%$ at 5 years $(16.4$ vs $13.9 \%)$ and $4.1 \%$ at 9 years (29.9 vs $25.8 \%$ ). However, there was no difference in overall survival, either among all randomised women or the HoR-positive tumour subgroup.

With a follow-up of 120 months, there was no difference in overall mortality in the HoR-positive subgroup (Cuzick et al. 2010).
Comparison of death rates at 33, 68 and 100 months of follow-up revealed that less deaths related to cancer recurrence were observed with anastrozole at 68 months, compared with tamoxifen, and the difference remained stable at 100 months (Table 4; Seruga \& Tannock 2009). In contrast, there were fewer deaths unrelated to cancer recurrence in the tamoxifen arm, and this difference continued to increase with time. Thus, long-term follow-up is mandatory because the persistence of this trend could modify the results in favour of tamoxifen.

\section{ARNO 95 trial}

In the ARNO 95 study, women were randomised after 2 years of tamoxifen treatment to continue tamoxifen or to switch to anastrozole for the remaining 3 years (Table 1; Kaufmann et al. 2007). The study included 969 patients of whom $97 \%$ had an HoR-positive tumour and 26\% had axillary lymph node involvement (Table 2). None of the patients received adjuvant chemotherapy. The primary endpoint was DFS, which included monitoring of local recurrences, distant recurrences, controlateral breast cancers and deaths (Table 3 ).

After a median follow-up of 30 months, there was a significant improvement in DFS (HR $=0.66 ; P=0.049)$ and overall survival $(\mathrm{HR}=0.53 ; P=0.045)$ in women who switched to anastrozole, corresponding to an absolute improvement of $4.2 \%$ in DFS (93.5 vs $89.3 \%$ ) and $2.6 \%$ in overall survival (96.9 vs $94.3 \%$ ).

Table 4 Number of deaths recorded in the ATAC trial during successive assessments and hazard ratio calculation (adapted from Diab (2005))

\begin{tabular}{|c|c|c|c|c|c|c|c|c|}
\hline \multirow{2}{*}{$\begin{array}{l}\text { Follow-up } \\
\text { (months) }\end{array}$} & \multicolumn{4}{|c|}{ Number of deaths with recurrence } & \multicolumn{4}{|c|}{ Number of deaths without recurrence } \\
\hline & Al & TAM & Difference & HR & Al & TAM & Difference & HR \\
\hline 33 & 122 & 122 & 0 & & 78 & 81 & -3 & \\
\hline 68 & 234 & 266 & -32 & $0.88(0.74-1.05)$ & 175 & 156 & 19 & $0.97(0.85-1.12)$ \\
\hline 100 & 350 & 382 & -32 & $0.91(0.79-1.05)$ & 279 & 242 & 37 & $1.12(0.94-1.33)$ \\
\hline
\end{tabular}

Al, aromatase inhibitor; TAM, tamoxifen; HR, hazard ratio. 


\section{ITA trial}

The ITA trial had a similar design to the ARNO-95 study in that women were randomised after 2-3 years of tamoxifen to continue tamoxifen or to switch to anastrozole (Table 1; Boccardo et al. 2006). The study included 448 patients, all with HoR-positive tumours and axillary lymph node involvement, and all of the patients had received chemotherapy before starting hormone therapy (Table 2). The primary endpoint was DFS, which included monitoring of locoregional and distant recurrences (Table 3). After a median follow-up of 64 months, the sequential regimen resulted in a significant improvement in DFS ( $\mathrm{HR}=0.56 ; P=0.01$ ), with no significant improvement in overall survival.

\section{ABCSG 8 trial}

In the ABCSG 8 study, tamoxifen treatment for 5 years was also compared with the sequence of tamoxifen followed by anastrozole (Table 1), but randomisation occurred prior to initiation of hormone therapy, and not 2-3 years after starting tamoxifen, as in the ARNO 95 and ITA trials (Jakesz et al. 2009). Initially, the study included 3901 women, of whom $25 \%$ had axillary lymph node involvement. None of the patients received adjuvant chemotherapy (Table 2). The primary endpoint was event-free survival (EFS), which included monitoring of locoregional and metastatic recurrences, controlateral breast cancers and deaths from any cause (Table 3 ).

The results of this study after median follow-up of 72 months were presented at the San Antonio Breast Cancer Symposium 2008 (Jakesz et al. 2009). Comparison of the treatment regimens was based on only 2922 women, the others being excluded for multiple reasons. EFS was significantly higher in women treated with the sequential regimen $(\mathrm{HR}=$ $0.79 ; P=0.038)$ as was overall survival $(\mathrm{HR}=0.77$; $P=0.025)$. As these conclusions do not apply to all the randomised women, caution should be taken when interpreting the results.

The results of this study were included in a meta-analysis with the ARNO 95 trial (Jakesz et al. 2005), and then in a second meta-analysis with the ARNO 95 and ITA trials (Jonat et al. 2006). However, the conclusions of these two meta-analyses are difficult to assess because the time of randomisation differed across the studies. In both meta-analyses, results of the ABCSG 8 trial were analysed beginning at the time of treatment switch and thus did not take into account the events that occurred during the first 2 years.

\section{ABCSG 6a trial}

This study evaluated the benefits of continuing anastrozole therapy after 5 years of hormone therapy (Table 1; Jakesz et al. 2007). It was an extension of the ABCSG 6 trial, which compared 5 years of tamoxifen versus 5 years of tamoxifen combined with aminoglutethimide (an older and less specific AI) during the first 2 years (Schmid et al. 2003). Women in the ABCSG 6 trial patients who did not have recurrence after 5 years of hormone therapy could be included in the ABCSG 6a trial, and 1135 patients underwent prerandomisation. Of these, 856 patients agreed to be included in the ABCSG 6a trial. Totally, 390 patients were assigned to the experimental arm receiving 3 years of anastrozole and 470 patients to the control arm, this unbalanced assignment being a potential cause of bias. Lymph node involvement was originally present in $25 \%$ of the women. None of them had received adjuvant chemotherapy (Table 2).

The primary endpoint was recurrence-free survival, which included monitoring of locoregional recurrences, distant recurrences and controlateral cancers (Table 3). Continuation of hormone therapy beyond the first 5 years resulted in a significant increase in recurrence-free survival $(\mathrm{HR}=0.62 ; P=0.031)$, with no improvement of overall survival.

\section{Randomised studies with letrozole}

\section{BIG 1-98 trial}

This double-blind study comprised four treatment arms: a reference arm of 5 years of tamoxifen, an experimental arm of 5 years of letrozole and two experimental arms of sequential treatment (tamoxifen followed by letrozole or letrozole followed by tamoxifen) (Table 1; Thürlimann et al. 2005). The study included 8010 women randomised to the four treatment arms, with all tumours being HoR positive. Lymph nodes were involved in $43 \%$ of the women and $25 \%$ also received adjuvant chemotherapy (Table 2). The primary endpoint was DFS, which included monitoring of locoregional recurrences, metastatic recurrences, controlateral breast cancers, any other cancer and deaths from any cause (Table 1). The definition of DFS differed from that used in the ATAC trial (Table 3).

Comparative results for 4922 women randomised to the two monotherapy arms were published after a median follow-up of 51 months (Coates et al. 2007). There was significantly better DFS (HR $=0.82$; $P=0.007)$ for women treated with letrozole but no 
significant difference in overall survival or distant DFS between these treatment arms.

More recently, updated results were published after a median follow-up of 76 months for the monotherapy arms and 71 months for the sequential arms (Mouridsen et al. 2009). After being informed of the improved DFS obtained with letrozole at a followup of 51 months, $25 \%$ of the women on the tamoxifen arm had decided to stop tamoxifen and switch to letrozole, rendering the analysis at 76 months difficult. Analysis according to initially administered treatment showed that DFS was significantly higher in the letrozole arm $(\mathrm{HR}=0.88 ; P=0.03)$, with 56 additional events (565 vs 509) in the tamoxifen arm $(n=2459)$ compared with the letrozole arm $(n=2463)$. Again, there was no difference in the overall survival $(\mathrm{HR}=$ $0.87 ; P=0.08$ ); although if women who had stopped tamoxifen in favour of letrozole were removed from analysis, the overall survival appeared to be significantly higher in the letrozole arm.

The letrozole arm was also compared with the two sequential arms, with a total of 4634 patients assigned to these three treatment groups (Mouridsen et al. 2009). There were no differences in DFS at 5 years: it was $87.9 \%$ in the letrozole arm, $87.6 \%$ in the sequential arm with letrozole followed by tamoxifen and $86.2 \%$ in the sequential arm with tamoxifen followed by letrozole.

These data were re-analysed in order to identify the subgroup that would benefit more from letrozole (Viale et al. 2011). A composite prognostic profile incorporating clinicopathological data (tumour size, positive lymph nodes and vascular invasion) and biological tumour markers (tumour grade, oestrogen receptor (ER)\%, progesterone receptor (PgR)\%, $\mathrm{Ki} 67 \%$ and HER2) was generated. This prognostic profile was able to predict the relative benefit of the treatment. Patients with high composite risk did better when treated with 5 years of letrozole. Any of the three letrozole-containing regimen appeared acceptable for patients with intermediate composite risk. Lowest risk patients did similarly well with letrozole monotherapy, sequential treatment or tamoxifen alone.

\section{MA 17 trial}

In this double-blind study, 5187 women, who had received adjuvant tamoxifen for 5 years, were randomised to receive either letrozole or placebo for up to 5 more years (Table 1; Goss et al. 2005). Axillary lymph node involvement had been present in $45 \%$ of the women and $45 \%$ of them had received chemotherapy (Table 2). The primary endpoint was DFS, defined as the interval between randomisation and occurrence of a locoregional recurrence, metastatic recurrence or controlateral breast cancer (Table 3).

At a median follow-up of 30 months, there was a significantly better DFS in women receiving letrozole (HR $=0.58 ; P<0.001)$, whereas overall survival did not significantly differ between the groups $(\mathrm{HR}=0.82$; $P=0.3$ ). Data analysis for the subgroup of patients with axillary lymph node involvement suggested an improvement in the overall survival for women who received letrozole $(\mathrm{HR}=0.61 ; P=0.04)$.

After publication of the initial results of the trial, 1579 patients from the placebo group chose to take letrozole, whereas 804 patients continued to take placebo (Goss et al. 2008). The median interval between discontinuation of tamoxifen and initiation of letrozole was 33 months. After a median follow-up of 5.3 years, a significant improvement in DFS was observed in patients treated with letrozole, and the authors concluded that even delayed letrozole after discontinuation of tamoxifen could reduce the risk of recurrence and death. These conclusions should be taken with caution because the analysis was performed retrospectively on two non-equivalent patient groups.

\section{Randomised studies with exemestane}

\section{IES trial}

In this double-blind study, 4724 women were randomised after 2-3 years of tamoxifen to continue tamoxifen or to switch to exemestane for the remainder of the 5-year treatment period (Table 1; Coombes et al. 2007). Of these women, $86 \%$ had HoR-positive tumours, $48 \%$ had positive axillary lymph nodes at surgery and $32 \%$ had received adjuvant chemotherapy (Table 2). The primary endpoint was DFS, which included monitoring of locoregional and metastatic recurrences, as well as deaths from any cause (Table 3 ).

After a median follow-up of 56 months, DFS was significantly better in women treated with the sequential regimen $(\mathrm{HR}=0.76 ; P=0.0001)$, corresponding to an absolute difference in DFS of 3.3 and $3.4 \%$ at 2.5 and 5 years after randomisation respectively. No significant difference in overall survival was observed for all randomised women $(\mathrm{HR}=0.85$; $P=0.08$ ), but there was significantly better overall survival in the subgroup of women with HoR-positive tumours who received the sequential regimen $(\mathrm{HR}=0.83 ; P=0.04)$.

Data were updated at the 2009 San Antonio Breast Cancer Symposium with a median follow-up of 91 months (Bliss et al. 2009). DFS remained significantly 
better in the sequential arm $(\mathrm{HR}=0.82 ; P=0.0009)$ with an absolute difference of $4.4 \%$. With the increased follow-up, overall survival was also significantly better for patients treated with exemestane $(\mathrm{HR}=0.86$, $P=0.04$ ) with an absolute difference of $2.4 \%$.

\section{NSABP B-33 trial}

This double-blind, placebo-controlled study assessed the benefit of exemestane treatment after 5 years of tamoxifen (Table 1; Mamounas et al. 2008). The primary endpoint was DFS, which included monitoring of locoregional or metastatic recurrences, second cancers and deaths from any cause (Table 3). The study started in 2001, with a plan to recruit 3000 women. Because the results of the MA 17 trial were presented in October 2003 showing improved DFS as a result of prolonging hormone therapy with letrozole, patient enrolment into the NSABP B33 trial was stopped, with 1598 patients included in the study. Data analysis at a median follow-up of 30 months showed a non-significant increase in DFS for patients who continued hormone therapy with exemestane $(\mathrm{HR}=0.68 ; P=0.07$; Mamounas et al. 2008).

\section{TEAM trial}

In this trial, 9775 women were randomised to a reference sequential arm consisting of tamoxifen followed by exemestane or to an experimental arm with 5 years of exemestane treatment (Table 1; Jones et al. 2009). The primary endpoint was DFS, which included monitoring of locoregional and metastatic recurrences, controlateral breast cancers, other primary cancers, and deaths from any cause (Table 3). Among women in this study, $48 \%$ had lymph node involvement and $36 \%$ had received adjuvant chemotherapy (Table 2 ).

With a median follow-up of 5.1 years, there was no significant difference in DFS between treatment arms (HR $=0.97, P=0.6$; Van de Velde et al. 2011).

\section{MA 27 trial}

This study included 7576 menopausal patients and compared 5 years of exemestane to 5 years of anastrozole (Goss et al. 2010). Axillary lymph node involvement had been present in $29 \%$ of the patients, and $31 \%$ of them had received chemotherapy. The hypothesis was the EFS improvement with exemestane. With a median follow up of 4.1 years, there was no difference in EFS ( $\mathrm{HR}=1.02(0.87-1.18), P=0.85)$ and overall survival (OS) $(\mathrm{HR}=0.93 \quad(0.77-1.13)$, $P=0.51)$ between the two arms.

\section{Discussion}

Regardless of the regimen, there was always an improvement in DFS when AI was included in the adjuvant hormone therapy for postmenopausal women with breast cancer. Comparison of the results among studies is difficult, due to the heterogeneous patient populations included in these studies, particularly with respect to axillary lymph node involvement and prescription of adjuvant chemotherapy. Moreover, there was substantial variability in the definition of DFS among the studies (Table 3).

Most of the studies did not show significant improvement in overall survival. A meta-analysis performed by the Early Breast Cancer Trialists' Collaborative Group included the monotherapy arms of the ATAC and BIG 1-98 trials, gathering data on 9856 patients treated for 5 years with tamoxifen or an AI with a median follow-up of 5.8 years (Dowsett et al. $2010 a, b)$. Adjuvant treatment with an AI was associated with a non-significant $1.1 \%$ decrease in 5-year mortality due to breast cancer with almost identical 5-year overall survival. In the ATAC trial, which has the longest follow-up (100 months), death rates related to breast cancer progression were lower in the anastrozole arm, but this apparent benefit was completely offset by increased death rates due to other causes in the anastrozole arm (Table 4; Smith \& Dowsett 2003).

The meta-analysis also evaluated 9015 patients in trials that evaluated continued tamoxifen versus an AI after 2-3 years of initial treatment with tamoxifen (i.e. the switching strategy) and reported an absolute benefit of $0.7 \%$ in breast cancer mortality at 3 years after treatment divergence $(P=0.01$; Dowsett et al. $2010 a, b)$. The meta-analysis also suggests a small but significant advantage in overall survival associated with the switching strategy, with a 3-year absolute gain of $1.1 \%(\mathrm{HR}=0.79 ; P=0.002)$. The difference in recurrence in favour of switching (and presumably in survival) is largely observed in women with nodepositive breast cancer.

The fundamental aim of any treatment for cancer is to improve either the duration or the quality of survival. Some would argue that a decrease or delay in recurrence of breast cancer, even in the absence of an improvement in overall survival, is a worthy goal, because improved DFS might be expected to be associated with better quality of survival. However, differences in quality of survival will depend on the adverse events associated with treatment. Side effects of AIs and tamoxifen have been described in detail elsewhere (Conte \& Frassoldati 2007, Hadji 2008). 
Both agents may cause exacerbation of menopausal symptoms, particularly in younger postmenopausal women, and cognitive changes (Agrawal et al. 2010). A prospective trial with 18 neuropsychological tests showed that $64 \%$ of patients (nine out of 14 patients) receiving anastrozole without chemotherapy had cognitive declines (Collins et al. 2009). Tamoxifen causes endometrial hyperplasia and rarely a second tumour of the uterus; it can stimulate blood clots in women with a history of prior events such as deep vein thrombosis (Colleoni \& Giobbie-Hurder 2010). AIs are more likely to cause muscle and joint symptoms, and unlike tamoxifen, they cause bone loss and increased fractures (Colleoni \& Giobbie-Hurder 2010). The profile of cardiovascular toxicities among AIs is different in published trials. No difference in the incidence of cardiovascular disease was reported between anastrozole and tamoxifen in the ATAC trial (Forbes et al. 2008), whether a trend towards an increased incidence of myocardial infarction was reported with letrozole in the BIG 1-98 trial (Coates et al. 2007). Overall, the tolerance of women for AIs appears to be poorer than for tamoxifen and premature discontinuation of AI therapy might compromise the potential benefit of these treatments. A retrospective study evaluated the discontinuation and non-adherence to hormonal adjuvant therapy in 8769 patients with HoR-positive tumours (Hershman et al. 2010). Over the 4.5-year follow-up, $20 \%$ of patients treated with tamoxifen were non-adherent to the prescription, whereas more than $40 \%$ of patients treated with AI were non-adherent.

Pharmaco-economic studies have been undertaken based on the early results of some of the trials, but they were based on the (at that time reasonable) assumption that early changes in DFS would translate into improvements in overall survival; they may also have suffered from bias because of sponsorship by companies that were marketing the AIs (Hind et al. 2007). There is a substantial difference in price of tamoxifen and AIs: 1 month of tamoxifen treatment costs about 10 Euros, whereas 1 month of treatment with an AI is about 15 times more expensive. Thus, in situations where an AI does not improve either overall survival or its quality, tamoxifen is far more cost-effective.

Based on the results of the trials, and the above considerations relating to toxicity and cost, we suggest that adjuvant therapy for postmenopausal women with HoR-positive breast cancer at high risk of recurrence (and low risk of toxicity from AIs) should include a period of treatment with an AI. Is it possible to agree upon the definition of high risk? In the ATAC trial, anastrozole was reported to reduce the risk of early recurrence during the first 2 years, and risk factors for early recurrence of HoR-positive tumours are high tumour grade, weak expression of HoRs and axillary lymph node involvement (Debled et al. 2007, Kennecke et al. 2008). Also, the BIG 1-98 trial was retrospectively analysed using the tumour proliferation marker Ki-67: letrozole led to superior DFS compared with tamoxifen in highly proliferative tumours, whereas no difference was observed in low proliferative tumours (Viale et al. 2008). In the ATAC trial, a retrospective analysis examined the influence of the Oncotype DX Recurrence Score (Dowsett et al. $2010 a, b)$, which is strongly correlated with tumour proliferation (Paik et al. 2004). This study confirmed that the recurrence score gives additional prognostic information to traditional factors in patients treated with either tamoxifen or an AI. Thus, a regimen that first includes an AI is probably a judicious choice for patients who meet criteria for high risk of recurrence, especially those who have node-positive disease. However, if current results of the BIG 1-98 trial are confirmed, switching to tamoxifen after 2 years of treatment with an AI seems appropriate.

The results of the trials reviewed above do not support the routine use of an $\mathrm{AI}$ in women at low risk of recurrence, except for the rare patient with a high probability of toxicity from tamoxifen, and perhaps also in patients with low CYP2D6 function or under medications that interfere with its metabolism (Punglia et al. 2008, Schroth et al. 2009, Seruga \& Tannock 2009, Kelly et al. 2010). It is uncertain whether AIs are associated with a small improvement in breast cancer mortality for such women, and even if a small difference was confirmed with longer follow-up, it must be weighed against the adverse events and substantially higher cost of AIs. For example, tamoxifen is known to exhibit protective effects against coronary diseases, whereas the cardiovascular effects of AIs are under evaluation (Nordenskjöld et al. 2005). According to the surveillance epidemiology and end results (SEER) database from the United States National Cancer Institute, women over 70 years treated for $\mathrm{pN} 0$ breast cancer have a greater risk of death from cardiovascular disease than from breast cancer (Diab 2005). The same logic applies to patients above 80 years of age treated for breast cancer with involvement of one to three axillary lymph nodes.

Continuing hormone therapy with an AI after 5 years of tamoxifen was shown to improve DFS, but we do not know whether these results are better than those obtained by switching among agents at $2-3$ years. The presence of axillary lymph node involvement is the 
major risk factor for late recurrence after 5 years (Kennecke et al. 2007). The ATLAS trial compared 5 years of tamoxifen to 10 years of tamoxifen in a total of 11500 patients. Continuing tamoxifen beyond 5 years resulted in a significant reduction in recurrence rates (Peto 2007). As yet, there is insufficient evidence to support continuation of hormone therapy with an AI after 5 years.

In conclusion, the introduction of AIs has provided more options for adjuvant treatment of postmenopausal women. AI are associated with improved DFS, but less commonly with improvement in OS. Current evidence suggests that women at high risk of recurrence, especially those with node-positive disease, should receive an $\mathrm{AI}$ as part of their treatment, but routine prescription of AIs to postmenopausal patients with low-risk disease is not appropriate. Not only the expected benefits but also the specific toxicity of the prescribed hormone therapy, and its cost, should be considered when selecting treatment.

\section{Declaration of interest}

The authors declare that there is no conflict of interest that could be perceived as prejudicing the impartiality of the research reported.

\section{Funding}

This research did not receive any specific grant from any funding agency in the public, commercial or not-for-profit sector.

\section{References}

Agrawal K, Onami S, Mortimer JE \& Pal SK 2010 Cognitive changes associated with endocrine therapy for breast cancer. Maturitas 67 209-214. (doi:10.1016/j.maturitas. 2010.07.004)

Baum M, Budzar AU, Cuzick J, Forbes J, Houghton JH, Klijn JG \& Sahmoud T 2002 Anastrozole alone or in combination with tamoxifen versus tamoxifen alone for adjuvant treatment of postmenopausal women with early breast cancer: first results of the ATAC randomised trial. Lancet 359 2131-2139. (doi:10.1016/S0140-6736(02) 09088-8)

Beatson GT 1896 On the treatment of inoperable cases of carcinoma of the mamma: suggestions for a new method of treatment with illustrative cases. Lancet 2 104-107. (doi:10.1016/S0140-6736(01)72307-0)

Bliss JM, Kilburn LS, Coleman RE, Forbes JF, Coates AS, Jones SE, Jassem J, Delozier T, Andersen J, Paridaens RJ et al. 2009 Disease related outcome with long-term follow-up: an updated analysis of the Intergroup Exemestane study. Cancer Research 69 (Suppl 1) Abstract 12. (doi:10.1158/0008-5472.SABCS-09-12)

Boccardo F, Rubagotti A, Guglielmini P, Fini A, Paladini G, Mesiti M, Rinaldini M, Scali S, Porpiglia M, Benedetto C et al. 2006 Switching to anastrozole versus continued tamoxifen treatment of early breast cancer. Updated results of the Italian tamoxifen anastrozole (ITA) trial. Annals of Oncology 17 10-14. (doi:10.1093/annonc/ md1941)

Bonneterre J, Buzdar A, Nabholtz JM, Robertson JF, Thürlimann B, von Euler M, Sahmoud T, Webster A \& Steinberg M 2001 Anastrozole is superior to tamoxifen as first-line therapy in hormone receptor positive advanced breast carcinoma. Cancer 92 2247-2258. (doi:10.1002/ 1097-0142(20011101)92:9<2247::AID-CNCR1570>3. $0 . \mathrm{CO} ; 2-\mathrm{Y})$

Brock RC 1952 The Life and Work of Astley Cooper. Edinburgh and London, UK: E\&S Livingstone, Ltd.

Coates AS, Keshaviah A, Thürlimann B, Mouridsen H, Mauriac L, Forbes JF, Paridaens R, Castiglione-Gertsch M, Gelber RD, Colleoni M et al. 2007 Five years of letrozole compared with tamoxifen as initial adjuvant therapy for postmenopausal women with endocrineresponsive early breast cancer: update of study BIG 1-98. Journal of Clinical Oncology 25 486-492. (doi:10.1200/ JCO.2006.08.8617)

Cole MP, Jones CT \& Todd ID 1971 A new anti-oestrogenic agent in late breast cancer. An early clinical appraisal of ICI46474. British Journal of Cancer 25 270-275. (doi:10. 1038/bjc.1971.33)

Colleoni M \& Giobbie-Hurder A 2010 Benefits and adverse effects of endocrine therapy. Annals of Oncology 21 (Suppl 7) 107-111. (doi:10.1093/annonc/mdq281)

Collins B, Mackenzie J, Stewart A, Bielajew C \& Verma S 2009 Cognitive effects of hormonal therapy in early stage breast cancer patients: a prospective study. Psychooncology 18 811-821. (doi:10.1002/pon.1453)

Conte P \& Frassoldati A 2007 Aromatase inhibitors in the adjuvant treatment of postmenopausal women with early breast cancer: putting safety issues into perspective. Breast Journal 13 28-35. (doi:10.1111/j.1524-4741.2006. 00359.x)

Coombes RC, Kilburn LS, Snowdon CF, Paridaens R, Coleman RE, Jones SE, Jassem J, Van de Velde CJ, Delozier T, Alvarez I et al. 2007 Survival and safety of exemestane versus tamoxifen after 2-3 years' tamoxifen treatment (Intergroup Exemestane Study): a randomised controlled trial. Lancet 369 559-570. (doi:10.1016/ S0140-6736(07)60200-1)

Cuzick J, Sestak I, Baum M, Buzdar A, Howell A, Dowsett M \& Forbes JF 2010 Effect of anastrozole and tamoxifen as adjuvant treatment for early-stage breast cancer: 10-year analysis of the ATAC trial. Lancet Oncology 11 1135-1141. (doi:10.1016/S1470-2045(10)70257-6)

Debled M, MacGrogan G, Brouste V, Mathoulin-Pelissier S, Durand M \& Mauriac L 2007 Prognostic factors of 
early distant recurrence in hormone receptor-positive, postmenopausal breast cancer patients receiving adjuvant tamoxifen therapy: results of a retrospective analysis. Cancer 109 2197-2204. (doi:10.1002/cncr. 22667)

Diab S 2005 Aromatase inhibitors are unlikely to improve overall survival in elderly patients with breast cancer. Breast Cancer Research and Treatment 94 (Suppl 1) abstract 5100 S242.

Dodds EC 1948 Oestrogens in the treatment of cancer. Postgraduate Medical Journal 24 295-298. (doi:10.1136/ pgmj.24.272.295)

Dowsett M, Cuzick J, Ingle J, Coates A, Forbes J, Bliss J, Buyse M, Baum M, Buzdar A, Colleoni M et al. 2010a Meta-analysis of breast cancer outcomes in adjuvant trials of aromatase inhibitors versus tamoxifen. Journal of Clinical Oncology 28 509-518. (doi:10.1200/JCO.2009. 23.1274)

Dowsett M, Cuzick J, Wale C, Forbes J, Mallon EA, Salter J, Quinn E, Dunbier A, Baum M, Buzdar A et al. 2010 b Prediction of risk of distant recurrence using the 21-gene recurrence score in node-negative and node-positive postmenopausal patients with breast cancer patients treated with anastrozole or tamoxifen: a TransATAC study. Journal of Clinical Oncology 28 1829-1834. (doi:10.1200/JCO.2009.24.4798)

Early Breast Cancer Trialists' Collaborative Group 1998 Tamoxifen for early breast cancer: an overview of the randomised trials. Lancet 351 1451-1467. (doi:10.1016/ S0140-6736(97)11423-4)

Forbes JF, Cuzick J, Buzdar A, Howell A, Tobias JS \& Baum M 2008 Effect of anastrozole and tamoxifen as adjuvant treatment for early-stage breast cancer: 100-month analysis of the ATAC trial. Lancet Oncology 9 45-53. (doi:10.1016/S1470-2045(07)70385-6)

Goss PE, Ingle JN, Martino S, Robert NJ, Muss HB, Piccart MJ, Castiglione M, Tu D, Shepherd LE, Pritchard KI et al. 2005 Randomized trial of letrozole following tamoxifen as extended adjuvant therapy in receptor-positive breast cancer: updated findings from NCIC CTG MA.17. Journal of the National Cancer Institute 97 1262-1271. (doi:10.1093/jnci/dji250)

Goss PE, Ingle JN, Pater JL, Martino S, Robert NJ, Muss HB, Piccart MJ, Castiglione M, Shepherd LE, Pritchard KI et al. 2008 Late extended adjuvant treatment with letrozole improves outcome in women with early-stage breast cancer who complete 5 years of tamoxifen. Journal of Clinical Oncology 26 1948-1955. (doi:10. 1200/JCO.2007.11.6798)

Goss PE, Ingle JN, Chapman J-AW, Ellis MJ, Sledge GW, Budd GT, Rabaglio M, Gelmon K, Shepherd L \& Pritchard KI 2010 Final analysis of NCIC CTG MA.27: a randomized phase III trail of exemestane versus anastrozole in postmenopausal women with hormone receptor positive primary breast cancer. Breast Cancer Research and Treatment 94 (Supplement 1) abstract S1.
Hadji P 2008 Menopausal symptoms and adjuvant therapyassociated adverse events. Endocrine-Related Cancer 15 73-90. (doi:10.1677/ERC-07-0193)

Harris JR, Lippman ME, Morrow M \& Osborne CK eds. Diseases of the Breast. Philadelphia, PA, USA: Lippincott Williams \& Wilkins 2006.

Hershman DL, Kushi LH, Shao T, Buono D, Kershenbaum A, Tsai WY, Fehrenbacher L, Lin Gomez S, Miles S \& Neugut AI 2010 Early discontinuation and nonadherence to adjuvant hormonal therapy in a cohort of 8769 earlystage breast cancer patients. Journal of Clinical Oncology 28 4120-4128. (doi:10.1200/JCO.2009.25.9655)

Hind D, Ward S, De Nigris E, Simpson E, Carroll C \& Wyld L 2007 Hormonal therapies for early breast cancer: systematic review and economic evaluation. Health Technology Assessment 11 131-134.

Howell A, Cuzick J, Baum M, Buzdar A, Dowsett M, Forbes JF, Hoctin-Boes G, Houghton J, Locker GY \& Tobias JS 2005 Results of the ATAC (Arimidex Tamoxifen, Alone or in Combination) trial after completion of 5 years' adjuvant treatment for breast cancer. Lancet $\mathbf{3 6 5}$ 60-62. (doi:10.1016/S0140-6736(05)74803-0)

Jakesz R, Jonat W, Gnant M, Mittlboeck M, Greil R, Tausch C, Hilfrich J, Kwasny W, Menzel C, Samonigg H et al. 2005 Switching of postmenopausal women with endocrineresponsive early breast cancer to anastrozole after 2 years' adjuvant tamoxifen: combined results of ABCSG trial 8 and ARNO 95 trial. Lancet 366 455-462. (doi:10.1016/ S0140-6736(05)67059-6)

Jakesz R, Greil R, Gnant M, Schmid M, Kwasny W, Kubista E, Mlineritsch B, Tausch C, Stierer M, Hofbauer F et al. 2007 Extended adjuvant therapy with anastrozole among postmenopausal breast cancer patients: results from the randomized Austrian Breast and Colorectal Cancer Study Group Trial 6a. Journal of the National Cancer Institute 99 1845-1853. (doi:10.1093/jnci/djm246)

Jakesz R, Gnant M, Griel R, Tausch C, Samonigg H, Kwasny W, Kubista E, Stierer M, Luschin G, Rüecklinger E et al. 2009 Tamoxifen and anastrozole as a sequencing strategy in postmenopausal women with hormone-responsive early breast cancer: updated data from the Austrian breast and colorectal cancer study group trial 8. Cancer Research 69 (Supplement 1) abstract 14. (doi:10.1158/ 0008-5472.SABCS-14)

Jonat W, Gnant M, Boccardo F, Kaufmann M, Rubagotti A, Zuna I, Greenwood M \& Jakesz R 2006 Effectiveness of switching from adjuvant tamoxifen to anastrozole in postmenopausal women with hormone-sensitive earlystage breast cancer: a meta-analysis. Lancet Oncology 7 991-996. (doi:10.1016/S1470-2045(06)70948-2)

Jones SE, Seynaeve C, Hasenburg A, Rae D, Vannetzel J-M, Paridaens R, Markopoulos C, Hozumi Y, Putter H, Hille E et al. 2009 Results of the first planned analysis of the TEAM (tamoxifen exemestane adjuvant multinational) prospective randomized phase III trial in hormone sensitive postmenopausal early breast cancer. Cancer Research 69 (Supplement 1) abstract 15. (doi:10.1158/ 0008-5472.SABCS-15) 
Kaufmann M, Jonat W, Hilfrich J, Eidtmann H, Gademann G, Zuna I \& von Minckwitz G 2007 Improved overall survival in postmenopausal women with early breast cancer after anastrozole initiated after treatment with tamoxifen compared with continued tamoxifen: the ARNO 95 study. Journal of Clinical Oncology 25 2664-2670. (doi:10.1200/JCO.2006.08. 8054)

Kelly CM, Juurlink DN, Gomes T, Duong-Hua M, Pritchard KI, Austin PC \& Paszat LF 2010 Selective serotonin reuptake inhibitors and breast cancer mortality in women receiving tamoxifen: a population based cohort study. BMJ 340 1-8. (doi:10.1136/bmj.c693)

Kennecke HF, Olivotto IA, Speers C, Norris B, Chia SK, Bryce C \& Gelmon KA 2007 Late risk of relapse and mortality among postmenopausal women with estrogen responsive early breast cancer after 5 years of tamoxifen. Annals of Oncology 18 45-51. (doi:10.1093/annonc/ mdl334)

Kennecke H, McArthur H, Olivotto IA, Speers C, Bajdik C, Chia SK, Ellard S, Norris B, Hayes M, Barnett J et al. 2008 Risk of early recurrence among postmenopausal women with estrogen receptor-positive early breast cancer treated with adjuvant tamoxifen. Cancer 112 1437-1444. (doi:10.1002/cncr.23320)

Mamounas EP, Jeong JH, Wickerham DL, Smith RE, Ganz PA, Land SR, Eisen A, Fehrenbacher L, Farrar WB, Atkins JN et al. 2008 Benefit from exemestane as extended adjuvant therapy after 5 years of adjuvant tamoxifen: intention-to-treat analysis of the National Surgical Adjuvant Breast And Bowel Project B-33 trial. Journal of Clinical Oncology 26 1965-1971. (doi:10. 1200/JCO.2007.14.0228)

Mouridsen H, Gershanovich M, Sun Y, Perez-Carrion R, Boni C, Monnier A, Apffelstaedt J, Smith R, Sleeboom HP, Jaenicke F et al. 2003 Phase III study of letrozole versus tamoxifen as first-line therapy of advanced breast cancer in postmenopausal women: analysis of survival and update of efficacy from the International Letrozole Breast Cancer Group. Journal of Clinical Oncology 21 2101-2109. (doi:10.1200/JCO.2003.04.194)

Mouridsen H, Giobbie-Hurder A, Goldhirsch A, Thürlimann B, Paridaens R, Smith I, Mauriac L, Forbes JF, Price KN, Regan MM et al. 2009 Letrozole therapy alone or in sequence with tamoxifen in women with breast cancer. New England Journal of Medicine 361 766-776. (doi:10. 1056/NEJMoa0810818)

Nordenskjöld B, Rosell J, Rutqvist LE, Malmström PO, Bergh J, Bengtsson NO, Hatschek T, Wallgren A \& Carstensen J 2005 Coronary heart disease mortality after 5 years of adjuvant tamoxifen therapy: results from a randomized trial. Journal of the National Cancer Institute 97 1609-1610. (doi:10.1093/jnci/dji342)

Paik S, Shak S, Tang G, Kim C, Baker J, Cronin M, Baehner FL, Walker MG, Watson D, Park T et al. 2004 A multigene assay to predict recurrence of tamoxifen-treated, node-negative breast cancer. New England Journal of Medicine 351 2817-2826. (doi:10. 1056/NEJMoa041588)

Paridaens RJ, Dirix LY, Beex LV, Nooij M, Cameron DA, Cufer T, Piccart MJ, Bogaerts J \& Therasse P 2008 Phase III study comparing exemestane with tamoxifen as firstline hormonal treatment of metastatic breast cancer in postmenopausal women: the European Organisation for Research and Treatment of Cancer Breast Cancer Cooperative Group. Journal of Clinical Oncology 26 4883-4890. (doi:10.1200/JCO.2007.14.4659)

Peto R \& on behalf of the ATLAS Collaboration 2007 ATLAS (Adjuvant Tamoxifen, Longer Against Shorter): international randomized trial of 10 versus 5 years of adjuvant tamoxifen among 11500 women preliminary results. Breast Cancer Research and Treatment 106 (Supplement 1) abstract 48 S5.

Punglia RS, Burstein HJ, Winer EP \& Weeks JC 2008 Pharmacogenomic variation of CYP2D6 and the choice of optimal adjuvant endocrine therapy for postmenopausal breast cancer: a modeling analysis. Journal of the National Cancer Institute 100 642-648. (doi:10.1093/ jnci/djn100)

Santen RJ \& Harvey HA 1999 Use of aromatase inhibitors in breast carcinoma. Endocrine-Related Cancer 6 75-92. (doi:10.1677/erc.0.0060075)

Schmid M, Jakesz R, Samonigg H, Kubista E, Gnant M, Menzel C, Seifert M, Haider K, Taucher S, Mlineritsch B et al. 2003 Randomized trial of tamoxifen versus tamoxifen plus aminoglutethimide as adjuvant treatment in postmenopausal breast cancer patients with hormone receptor-positive disease: Austrian breast and colorectal cancer study group trial 6. Journal of Clinical Oncology 21 984-990. (doi:10.1200/JCO.2003.01.138)

Schroth W, Goetz MP, Hamann U, Fasching PA, Schmidt M, Winter S, Fritz P, Simon W, Suman VJ, Ames MM et al. 2009 Association between CYP2D6 polymorphisms and outcomes among women with early stage breast cancer treated with tamoxifen. Journal of the American Medical Association 302 1429-1436. (doi:10.1001/jama.2009. 1420)

Seruga B \& Tannock IF 2009 Up-front use of aromatase inhibitors as adjuvant therapy for breast cancer: the emperor has no clothes. Journal of Clinical Oncology 27 840-842. (doi:10.1200/JCO.2008.19.5594)

Smith IE \& Dowsett M 2003 Aromatase inhibitors in breast cancer. New England Journal of Medicine 348 2431-2442. (doi:10.1056/NEJMra023246)

Thürlimann B, Keshaviah A, Coates AS, Mouridsen H, Mauriac L, Forbes JF, Paridaens R, Castiglione-Gertsch M, Gelber RD, Rabaglio M et al. 2005 A comparison of letrozole and tamoxifen in postmenopausal women with early breast cancer. New England Journal of Medicine 353 2747-2757. (doi:10.1056/NEJMoa052258)

Van de Velde CJ, Rea D, Seynaeve C, Putter H, Hasenburg A, Vannetzel JM, Paridaens R, Markopoulos C, Hozumi Y, Hille ET et al. 2011 Adjuvant tamoxifen and exemestane 
in early breast cancer (TEAM): a randomised phase 3 trial. Lancet 377 321-331. (doi:10.1016/S0140-6736(10) 62312-4)

Viale G, Giobbie-Hurder A, Regan MM, Coates AS, Mastropasqua MG, Dell'Orto P, Maiorano E, MacGrogan G, Braye SG, Ohlschlegel C et al. 2008 Prognostic and predictive value of centrally reviewed Ki-67 labeling index in postmenopausal women with endocrine-responsive breast cancer: results from Breast International Group Trial 1-98 comparing adjuvant tamoxifen with letrozole. Journal of Clinical Oncology 26 5569-5575. (doi:10.1200/JCO.2008.17.0829)
Viale G, Regan MM, Dell'orto P, Mastropasqua MG, Maiorano E, Rasmussen BB, Macgrogan G, Forbes JF, Paridaens RJ, Colleoni M et al. 2011 Which patients benefit most from adjuvant aromatase inhibitors? Results using a composite measure of prognostic risk in the BIG 1-98 randomized trial. Annals of Oncology [in press]. (doi:10.1093/annonc/mdq738)

\author{
Received in final form 3 February 2011 \\ Accepted 18 April 2011 \\ Made available online as an Accepted Preprint \\ 18 April 2011
}

